\title{
Letter from the Editor and Deputy Editor
}

We are pleased to announce the establishment of a new international co-hosting arrangement between the Copenhagen Business School (CBS) and the McDonough School of Business (MSB) at Georgetown University. This arrangement has been approved by the AIB Executive Board, and it is now fully operational. In addition to alleviating some of the problems that have been encountered during the past couple of years, this arrangement will create new opportunities for expanding the Journal's services, enhancing its profile, and increasing its impact.

Catherine Langlois remains as the Deputy Editor in the office at Georgetown, and she is joined there by a new Managing Editor, Laura Lawson. We are in constant contact by e-mail, fax, and phone. We have worked out a detailed division of labor with the approval of the AIB Board, and we have become an efficient Trans-Atlantic team.

The establishment of the co-hosting arrangement was possible because of the co-operation of many people at both host institutions as well as of the AIB Executive Board. We would like to thank, in particular, Jose de la Torre, Jeff Arpan, and Don Lessard for their support during the past couple of years, and especially during the past six months. In addition, Jim Wills and Laurel King at the AIB office were very helpful as the new co-hosting arrangements were being established. Working with these AIB people has been a privilege.

A large number of people at CBS have been instrumental in facilitating the transition to the co-hosting arrangement. Within the Institute for International Economics and Management, Poul Schultz, Head, and Anne Mette Dissing, Administrative Director, have worked closely with Tom Brewer for six months. In addition, Finn Junge-Jensen, President; Gert Bechlund, Dean of the Economics Faculty; and Lauge Stetting, Director of CBS Press; have all been enormously helpful.

At Georgetown, Persa Economou, the previous Managing Editor, who left for a new and exciting professional position during the Journal transition period, was a tremendous help. We will miss her. But we are pleased that the new Managing Editor, Laura Lawson, was able to assume daily responsibilities for running the Journal in the difficult transition period. She not only had to learn a new job, at the same time she had to help us establish a large number of new procedures to keep the activities of the two offices well co-ordinated. In addition, by unhappy coincidence, she and Catherine Langlois had to move the Journal's editorial offices to new quarters at Georgetown while the co-hosting operations were being put into place. We are also pleased that Dean Chris Puto and Director of Faculty Services Virginia Flavin at Georgetown were so generous in their co-operation during the transition. We are grateful for their help.

There have been several concomitant changes in the Journal's procedures and services. In particular, we have adopted a new, expedited, e-mail-based review process that we believe is both author- and reviewer-friendly. Many of you have already encountered this new system in recent weeks when you submitted papers or when we sent you papers for review. We would like to hear your views on the system at jibs@msb.edu if you have not already communicated them to us. The details of the new submission requirements for authors are presented in a letter from the editorial team in the front matter of Volume 30, Number 2 (Second Quarter 1999).

There is also an enrichment of the web site in progress, being undertaken at CBS. The results and details of this process will become apparent from time to time on the web site in coming months.

This is an example of how the combined resources of the two host institutions will enable us to serve the members of the AIB and other readers of the Journal better.

Sincerely,

Thomas L. Brewer, Editor

Catherine Langlois, Deputy Editor 